\title{
MEGABAHITA LINNAVUORI \& DELONG (HOMOPTERA, CICADELLIDAE, DELTOCEPHALINAE): DESCRIÇÃO DE TRÊS ESPÉCIES NOVAS ${ }^{1}$
}

\author{
Keti Maria Rocha Zanol ${ }^{2}$
}

\begin{abstract}
MEGABAHITA LINNAVUORI \& DELONG (HOMOPTERA, CICADELLIDAE, DELTOCEPHALINAE): DESCRIPTION OF THREE NEW SPECIES. The genus Megabahita Linnavuori \& DeLong, 1978 is redefined based on the type species, M. irrorata (Osborn, 1923). A checklist is added and three new species are described: M. mineira sp.n., M. danunciae sp.n. and $\mathbf{M}$. spatulata sp.n., all from Brazil.

KEY WORDS. Megabahita, Deltocephalinae, Cicadellidae, Homoptera, Taxonomy
\end{abstract}

O material estudado pertence às seguintes instituições: Coleção de Entomologia Pe J.S. Moure, Departamento de Zoologia, Universidade Federal do Paraná, Curitiba, Paraná, PR (DZUP) e Museu Nacional do Rio de Janeiro, Universidade Federal do Rio de Janeiro, Rio de Janeiro,RJ(MNRJ). As espécies cujos nomes acham-se precedidos de asteríscos não foram examinadas.

\section{Megabahita Linnavuori \& DeLong, 1978}

Megabahita Linnavuori \& DeLong, 1978: 120.

Espécie-tipo: Eutettix irroratus Osborn, 1923 (Designação original)

Cabeça. Coroa de comprimento uniforme. Região frontal voltada para cima, esculturada. Margem anterior esculturada. Região discal lisa e com leves estrias longitudinais. Sutura coronal alcançando a metade do comprimento da coroa. Ocelos visíveis de cima. Sutura frontoclipeal terminando nos ocelos. Anteclípeo mais largo no ápice, plano ou levemente túmido no meio. Genas com reentrância abaixo dos olhos.

Pronoto tão largo quanto a cabeça; superfície lisa, às vezes com leve rugosidade transversa; margens laterais carenadas, longas. Tégminas sem falsas veias; com 2 células anteapicais, a externa ovalada. Clavo com veias extranumerárias entre as anais e a sutura claval. Veia transversa presente (raramente ausente). Apêndice longo, alcançando a $\mathrm{M}_{3}+4$. Espinulação dos fêmures posteriores $2+2+1$; das tíbias anteriores $1+4$.

1) Contribuição número 763 do Departamento de Zoologia da Universidade Federal do Paraná.

2) Departamento de Zoologia da Universidade Federal do Paraná e Centro de Identificação de Insetos Fitófagos (CIIF). Caixa Postal 19020, 81531-970 Curitiba, Paraná, Brasil. 

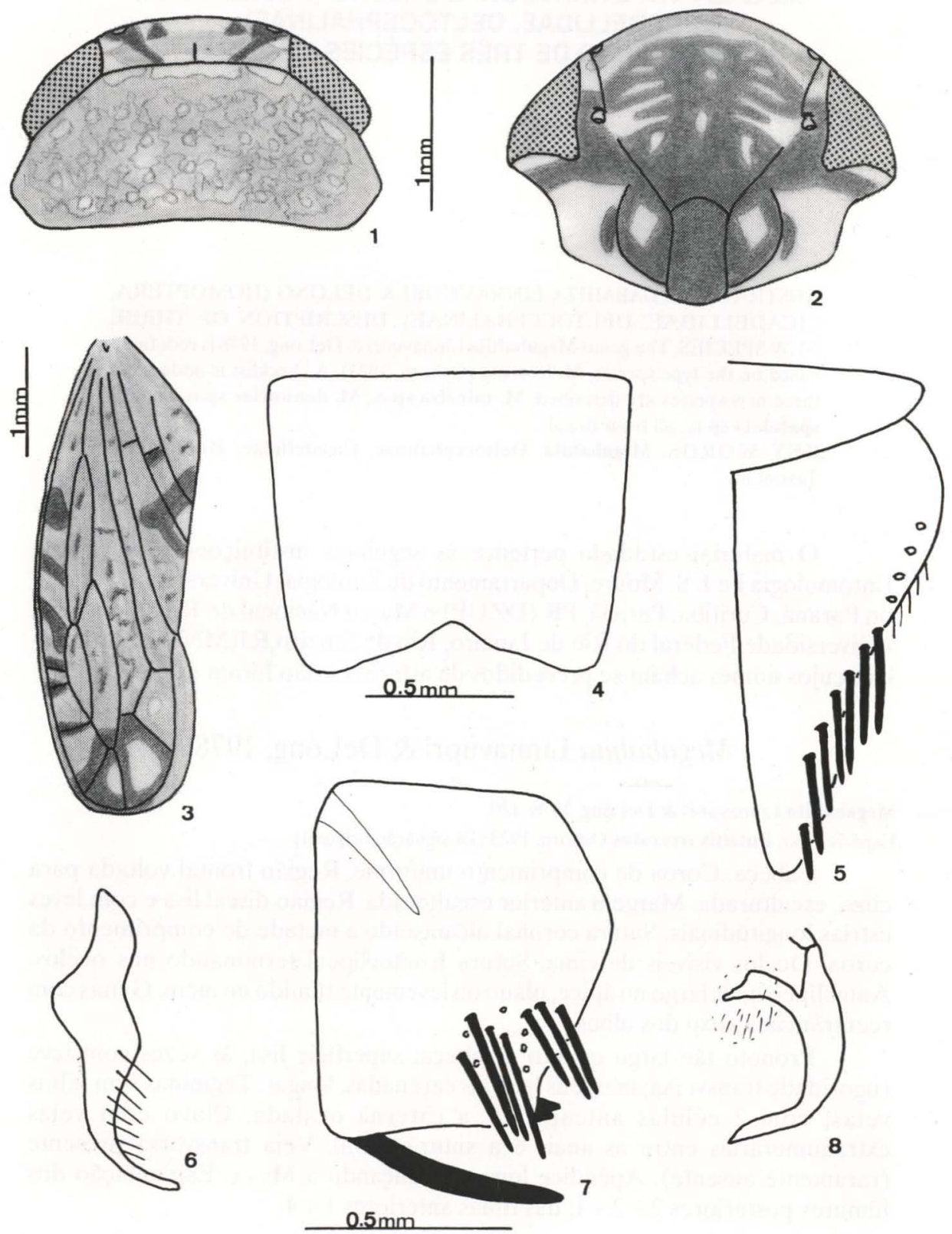

Figs 1-8. Megabahita irrorata (Osborn) - Holótipo. (1) Cabeça e pronoto em vista dorsal; (2) face; (3) tégmina; (4) placa subgenital da fêmea; (5) valva genital e placa subgenital do macho; (6) estilo; (7) pigóforo em vista lateral; (8) edeago em vista lateral. 
Genitália. Fêmea: placa subgenital com fenda mediana. Macho: placa subgenital triangular com macrocerdas unisseriadas; pigóforo com macrocerdas e apêndices; conetivo de braços paralelos; edeago simétrico, sem apêndices, base projetada em apódema; fragma com tufo de pequenos pêlos.

Espécies incluídas

M. danunciae, sp.n. - Brasil (Mato Grosso, São Paulo).

M. gigantea Linnavuori \& DeLong, 1978 - Brasil (Goias, São Paulo)

M. irrorata(Osborn, 1923) - Brasil (Mato Grosso, Goias, Bahia,São Paulo, Santa Catarina). Bolívia. Paraguai.

M. mineira, sp.n. - Brasil (Minas Gerais)

* M. patula DeLong, 1982 - Panamá

M. spatulata, sp.n. - Brasil (Mato Grosso)

*M. stylata DeLong, 1984 - Bolívia

\section{Megabahita irrorata (Osborn, 1923)}

Figs 1-8

Coloração: Coroa amarela; margem anterior com quatro manchas marrom-escuras: duas no meio, mais ou menos triangulares e uma junto a cada ocelo; esta projeta-se obliquamente para trás em direção à sutura coronal e à área entre elas castanho-amarelada. Face amarela com uma barra marrom-clara entre os ocelos; anteclípeo marrom-escuro; lora margeadas de marrom-escuro; frontoclípeo com o terço apical e uma faixa longitudinal projetada para os lados formando arcos marrom-escuros. Genas com mancha marrom-escura junto à sutura frontoclipeal contornando os alvéolos antenais e expandida para os lados em direção aos olhos até a margem. Pronoto castanho-amarelado irrorado de marrom-escuro. Tégminas marrons, semitransparentes com manchas marromescuras e áreas concolores.

Genitália. Fêmea: placa subgenital com fenda mediana; superfície com carena mediana. Macho: valva genital triangular com ângulos arredondados; placa subgenital triangular, com ápice arredondado; pigóforo com um par de apêndices ventro-apicais e um par de processos esclerotinizados, serreados, dorso-apicais; estilos digitiformes, com pêlos próximos ao ângulo préapical, curtos, não ultrapassando a metade do comprimento da placa; edeago curvo para cima, o terço apical, em vista lateral, mais ou menos achatado, sem apêndices.

\section{Megabahita mineira, sp.n.}

Figs 9-15

Padrão de coloração como em $M$. irrorata .

Macho. Genitália: pigóforo com um par de apêndices falciformes ventroapicais e duas projeções denticuladas, esclerotinizadas: a maior dorso-apical e a outra dorsal; estilos falciformes; edeago com apódema basal de comprimento 

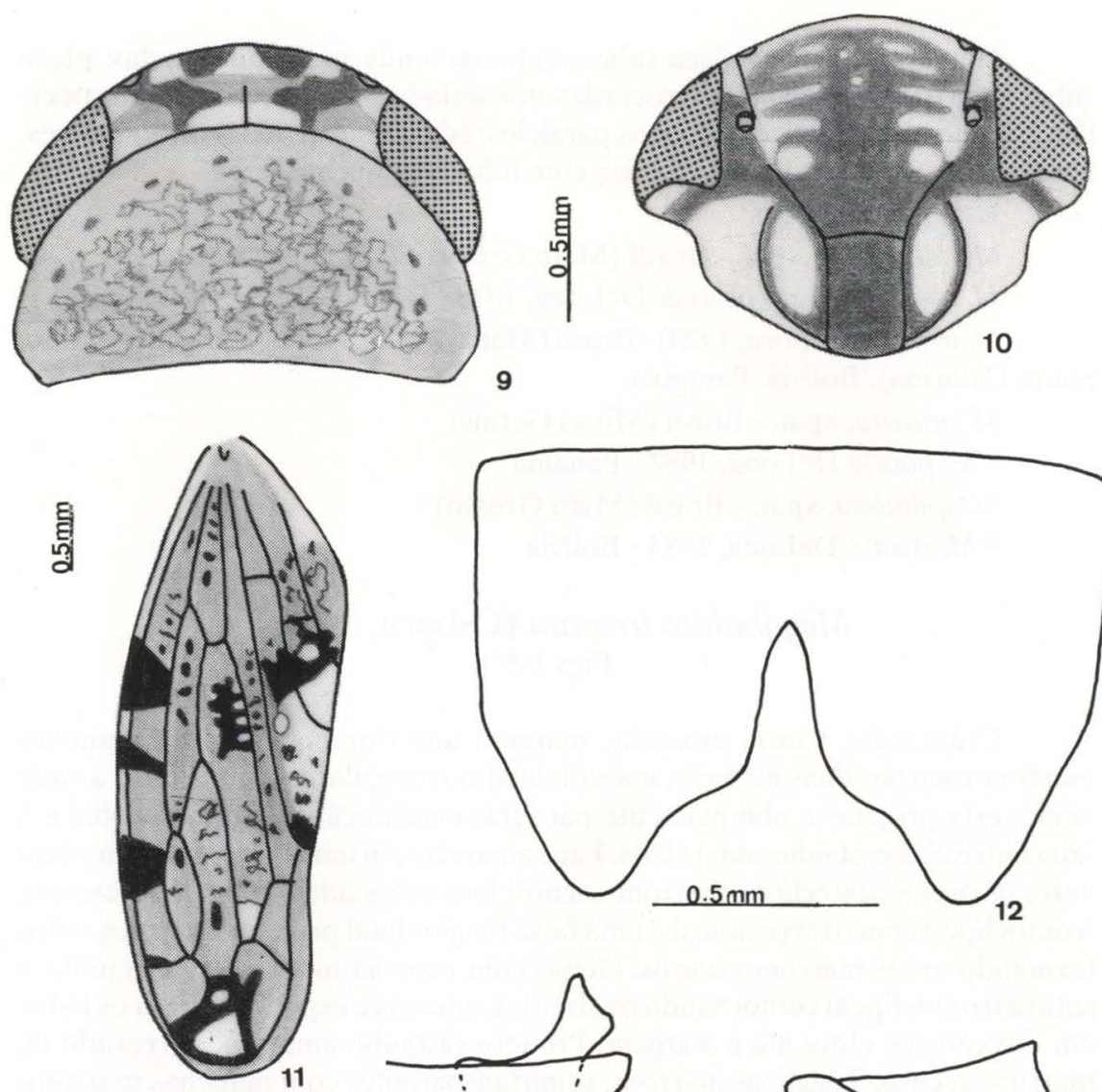

9
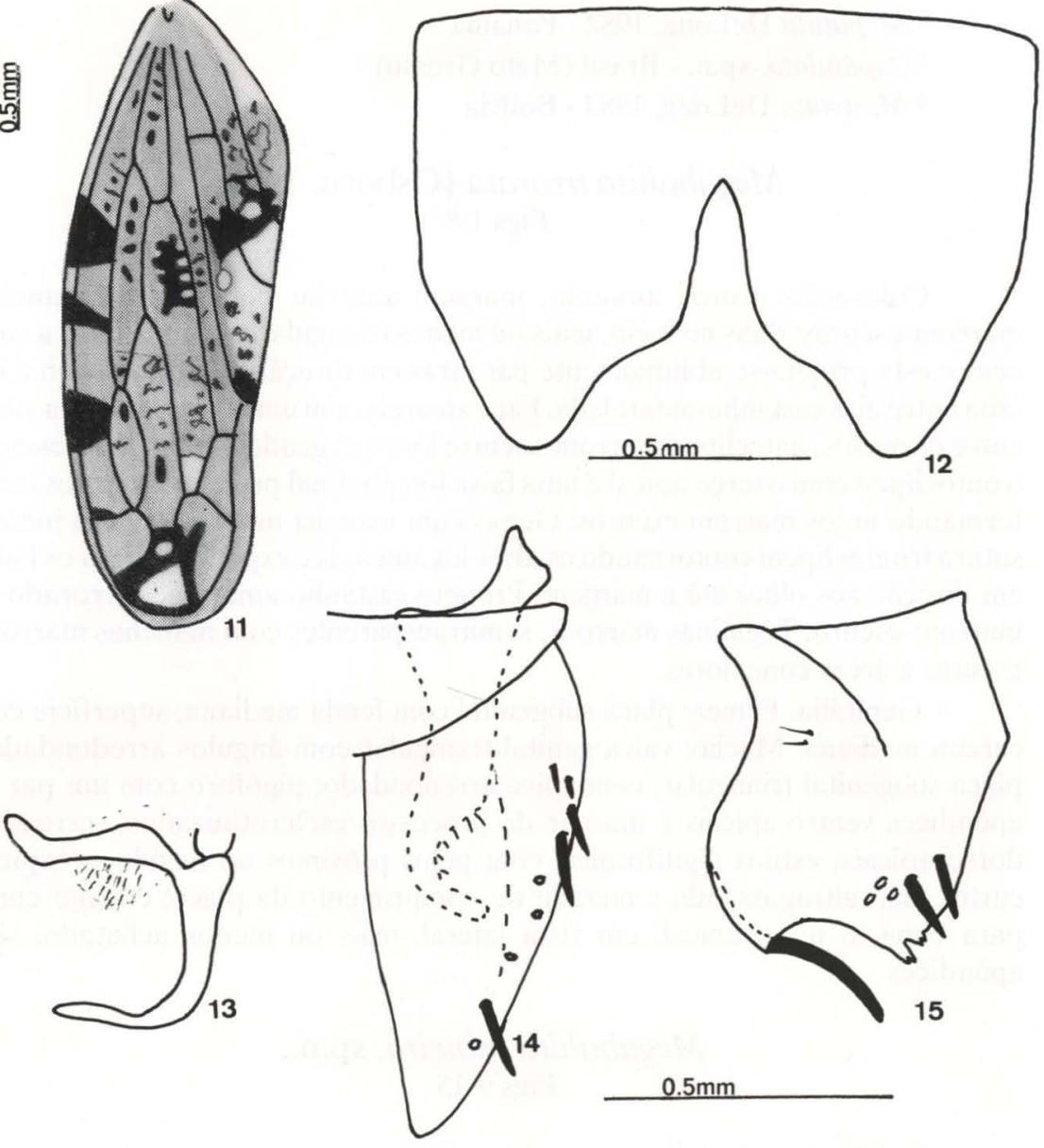

Figs 9-15. Megabahita mineira, sp.n. - Holótipo. (9) Cabeça e pronoto em vista dorsal; (10) face; (11) tégmina; (12) placa subgenital da fêmea; (13) edeago em vista lateral; (14) valva genital, placa subgenital e estilo; (15) pigóforo em vista lateral. 
maior do que a metade do seu comprimento.

Fêmea: Cabeça, às vezes, mais estreita que o pronoto. Placa subgenital com margem posterior oblíqua, levemente sinuosa, com uma fenda mediana atingindo a metade do seu comprimento.

Tamanho. Macho: $6,40 \mathrm{~mm}$, fêmea: $7,30 \mathrm{~mm}$

Material examinado. Holótipo macho do Brasil, Minas Gerais, Pirapora, XI.1975, M. Alvarenga leg. Alótipo e Parátipos: 1 macho e 1 fêmea da mesma localidade e data (DZUP).

Discussão: Esta espécie é muito próxima a $M$. irrorata mas o pigóforo do macho apresenta dois processos denticulados; o apódema do edeago de comprimento superior à metade do seu comprimento; a apófise do estilo falciforme $\mathrm{e}$ o edeago mais robusto. A fenda da placa subgenital da fêmea três vezes maior do que em $M$. irrorata.

\section{Megabahita danunciae, sp.n.} Figs 16-23

Macho. Coloração mais clara do que na fêmea. Margem anterior da coroa com quatro manchas marrons: duas mais ou menos triangulares e uma junto a cada ocelo; região discal castanho-amarelada em quase toda sua extensão. Genitália: placa subgenital com macrocerdas saindo longe da margem; pigóforo com um processo digitiforme, ventro-apical; estilos tortuosos, ultrapassando a metade do comprimento da placa, apófise voltada para dentro (semelhante a M. stylata); edeago com apódema de comprimento superior a metade do seu próprio comprimento.

Fêmea. Coloração como em M. irrorata. Anteclípeo levemente túmido no meio. Clavo com duas veias extranumerárias entre as anais e uma entre a $1 \mathrm{~A}$ e a sutura claval. Placa subgenital com a margem posterior obliquamente sinuosa, com uma fenda mediana, em forma de $\mathrm{V}$ invertido, ultrapassando a metade do seu comprimento.

Tamanho. Macho: 6,90-7,50 mm, fêmea. 7,70mm

Material examinado. Holótipo fêmea do Brasil, São Paulo, Botucatu, 31.I.1970, O.J.Chamma leg. Alótipo do Brasil, Mato Grosso, Chapada dos Guimarães, XI.63, M. Alvarenga leg. Parátipos. 1 fêmea da mesma localidade e data e 3 machos: 2 do BRASIL, São Paulo, Rubião Junior, 15-II-1973, M. Menezes leg (DZUP). E 1 com etiqueta 3481 (MNRJ).

Variação intraespecífica: o parátipo fêmea apresenta na margem posterior do pronoto uma concavidade mediana em forma de $\mathrm{V}$ e o clavo possui veia extranumerária somente entre as anais. Um dos exemplares de Rubião Júnior, com as veias anais fundidas pouco antes da veia extranumerária existente entre $1 \mathrm{~A}$ e a sutura.

Discussão: Esta espécie é muito semelhante a $M$. gigantea mas com anteclípeo levemente túmido no meio e a fenda da placa subgenital da fêmea em forma de "V" bem pronunciado. 

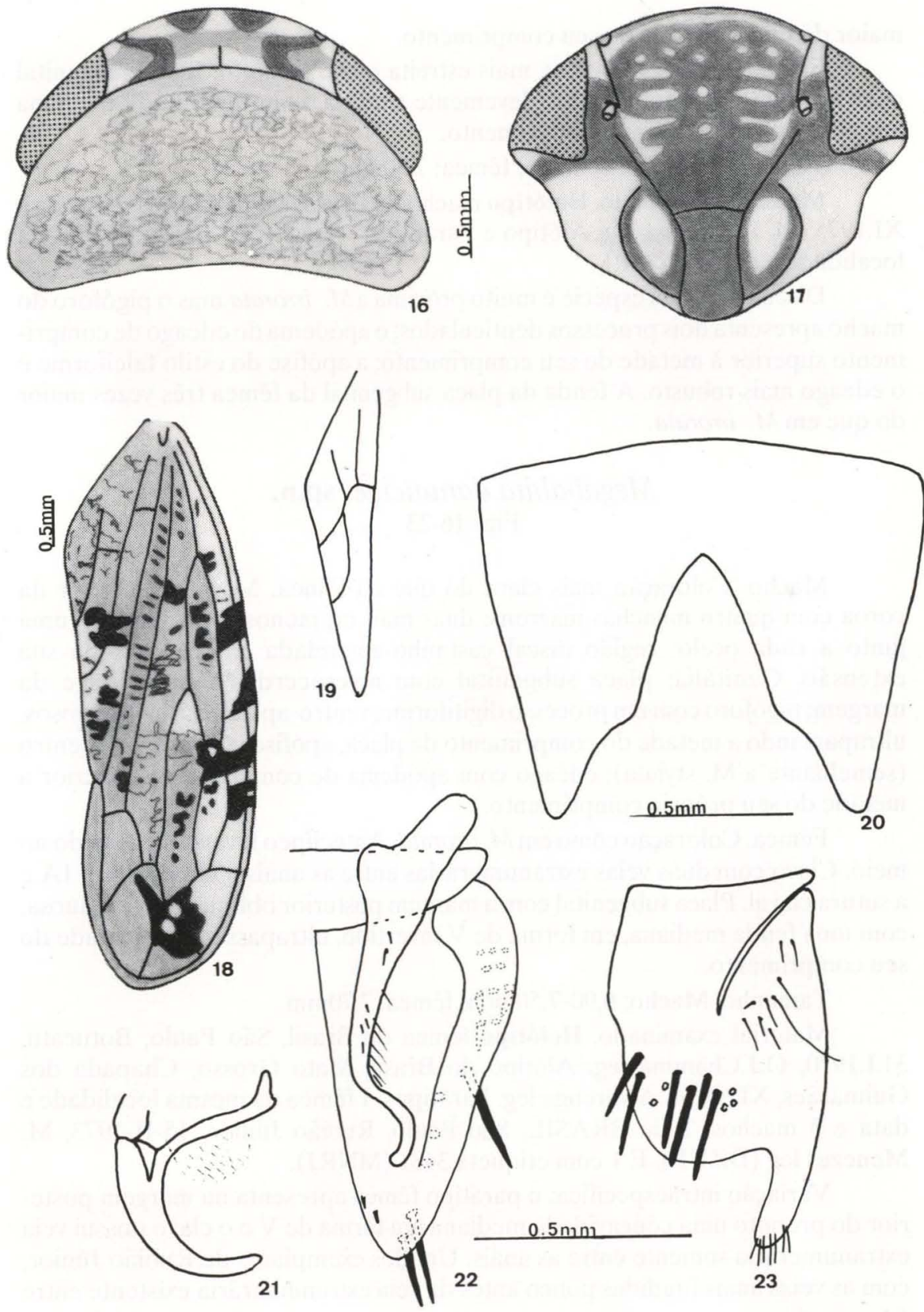

Figs 16-23. Megabahita danunciae, sp.n. - Holótipo. (16) Cabeça e pronoto em vista dorsal; (17) face; (18) tégmina; (19) clavo (parátipo); (20). placa subgenital da fêmea; (21) edeago em vista lateral; (22) valva genital, placa subgenital e estilo; (23) pigóforo em vista lateral. 

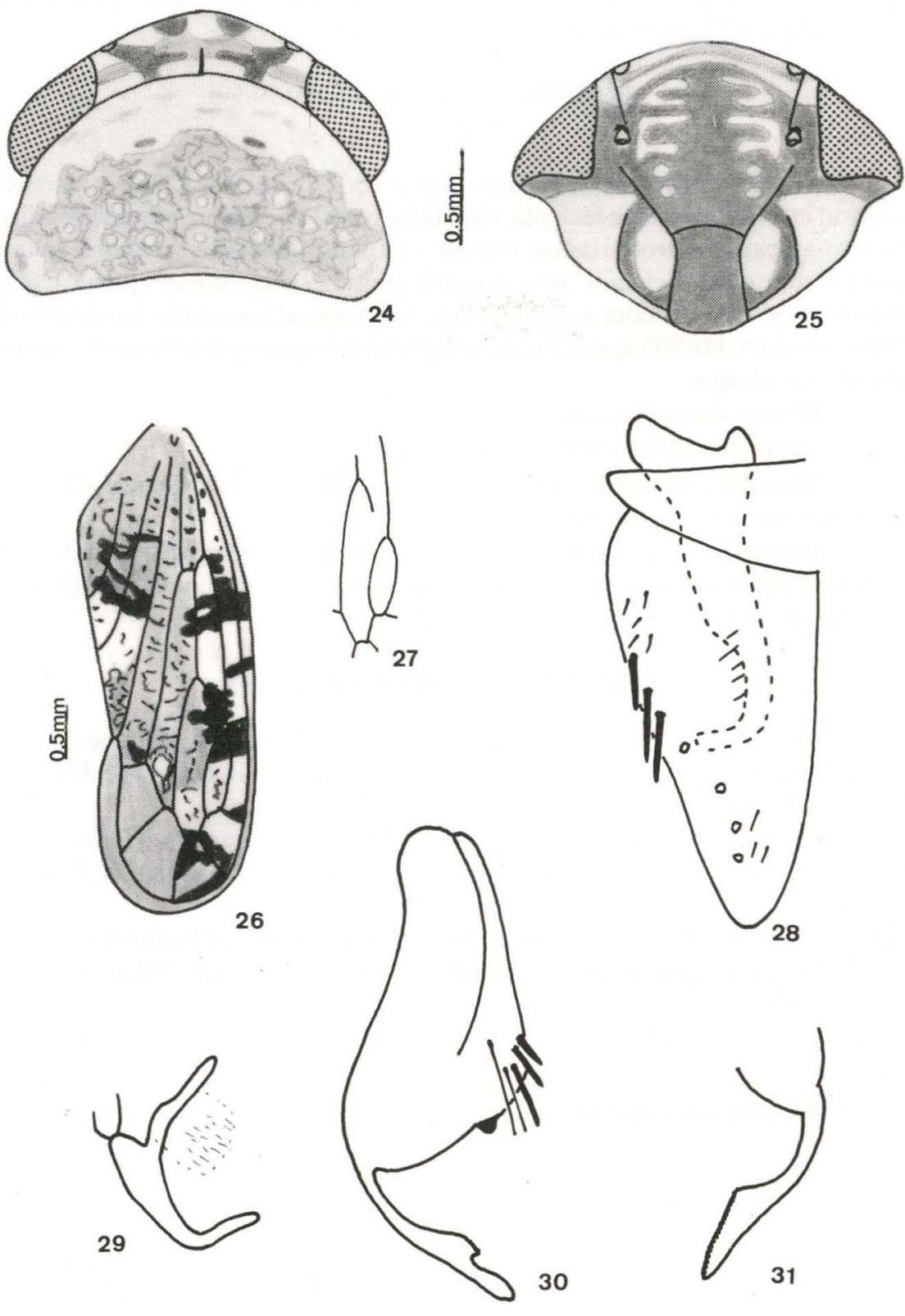

Figs 24-31. Megabahita spatulata, sp.n. - Holótipo. (24) Cabeça e pronoto em vista dorsal; (25) face; (26) tégmina; (27) células anteapicais; (28) valva genital, placa subgenital e estilo; (29) edeago em vista lateral; (30) pigóforo em vista lateral; (31) apêndice do pigóforo. 
Esta espécie é dedicada à Professora Danuncia Urban do Departamento de Zoologia da Universidade Federal do Paraná.

\section{Megabahita spatulata, sp.n.}

Figs 24-31

Macho. Padrão de coloracão como em $M$. irrorata. Célula anteapical central incompletamente fechada. Genitália: pigóforo com um par de apêndices ventro-apicais esclerotinizados; metade apical espatulada e serreada, voltada para frente e para cima e uma pequena protuberância dorso apical. Estilos falciformes. Edeago com a curvatura do terço apical formando um ângulo de aproximadamente $90^{\circ}$; apódema de comprimento superior à metade do comprimento do edeago.

Fêmea: desconhecida

Tamanho. Macho: 6,0mm.

Material examinado. Holótipo macho do Brasil, Mato Grosso, Chapada do Guimarães, XI.63, M. Alvarenga (DZUP).

Discussão. Esta espécie é muito próxima de $M$. irrorata;os apêndices do pigóforo em $M$. irrorata são mais falciformes enquanto que em $M$. spatulata são distintamente espatulados e serreados.

\section{REFERÊNCIAS BIBLIOGRÁFICAS}

DELONG, D.M. 1982. New Central and South America leafhoppers of the "Bahita" group (Homoptera: Cicadellidae:Deltocephalinae). Proc. Entomol. Soc. Wash. 84 (1): 184-190

- 1984. New leafhoppers of the "Bahita" group (Homoptera: Cicadellidae: Deltocephalinae) from Central and South America. Brenesia 22: $115-122$

LINNAVUORI, R. \& D.M. DELONG. 1978. Neotropical leafhoppers of the Bahita group (Homoptera:Cicadellidae: Deltocephalinae). Brenesia 14-15: 109-169

Recebido em 02XI.1992; aceito em 07.VI.1993. 